\title{
3 Research Square

\section{Seroconversion for SARS-CoV-2 in rheumatic patients on synthetic and biologics Disease Modifying Anti-Rheumatic Drugs in São Paulo, Brazil}

\section{Felipe M Santana}

Clínica de Reumatologia Prof. Dr. Castor Jordão Cobra

Jaqueline B Lopes

Clínica de Reumatologia Prof. Dr. Castor Jordão Cobra

Mariana O Perez

Clínica de Reumatologia Prof. Dr. Castor Jordão Cobra

Gustavo Campana

DASA

José Eduardo Levi

DASA

Flávia PPL Lopes

DASA

Otávio Gebara

Hospital Santa Paula

Jayme F Cobra

Clínica de Reumatologia Prof. Dr. Castor Jordão Cobra

Camille P Figueiredo ( $\nabla$ figueiredocamille@gmail.com )

Clínica de Reumatologia Prof. Dr. Castor Jordão Cobra

\section{Research Article}

Keywords: Autoimmune diseases, virus diseases, antirheumatic agents, biologic agents

Posted Date: November 19th, 2020

DOI: https://doi.org/10.21203/rs.3.rs-97191/v2

License: (c) (i) This work is licensed under a Creative Commons Attribution 4.0 International License.

Read Full License 


\section{Abstract}

Introduction - To date, there is a lack of information on how immunomodulatory drugs for autoimmune rheumatic diseases (ARDs) impair humoral immune response following SARS-CoV-2 exposure. Hence, we examined anti-SARS-CoV-2 IgG/lgM positivity in ARD patients on disease-modifying anti-rheumatic drugs (DMARDs).

Methods - We conducted a prospective study with ARD patients on different synthetic or biologic DMARDs (sDMARDs or bDMARDs) and control patients without DMARDs. All patients underwent a clinical baseline interview. They were tested for anti-SARS-CoV-2 IgG/lgM at baseline and three months later. Patients were monitored for incident respiratory symptoms during the follow-up. rRT-PCR for SARSCoV-2 was performed for suspected COVID-19 infection. A univariate analysis was conducted according to antibody positivity to find significant associations for seroconversion.

Results - We included one hundred patients for the analysis. Half of the patients who turned IgG positive in the study remained asymptomatic. All positive rRT-PCR patients showed seroconversion for anti-SARSCoV-2 IgG. A borderline significant association was found for bDMARD use in IgG-positive patients ( $42.9 \%$ vs. $19.8 \%, p=0.056)$. On the other hand, none of the patients on non-antimalarial SDMARD had detectable anti-SARS-CoV-2 IgG compared to $35.4 \%$ of the remainder of the sample, reaching borderline statistical significance $(0.0 \%$ vs. $35.4 \%, \mathrm{p}=0.050)$.

Conclusions - Serology for COVID-19 yielded a 14\% incidence in our sample, half evolving asymptomatically. Temporally withholding bDMARD therapy in ARD patients during the pandemic based on possible humoral response impairment is not suitable. SDMARD was associated with a lower incidence of anti-SARS-CoV-2 IgG positivity, and further studies on this possible impact are warranted.

\section{Key Messages}

- Synthetic and biologic DMARDs may impair the humoral immunologic response to infectious insults;

- Their use might compromise further antibody seroconversion in SARS-CoV-2;

- Synthetic DMARDs were associated with a lower incidence of anti-SARS-CoV-2 IgG positivity.

\section{Introduction}

Coronavirus disease 2019 (COVID-19), caused by a newly described beta coronavirus known as severe acute respiratory syndrome coronavirus 2 (SARS-CoV-2 virus) [1], has spread worldwide since the first official case was reported in Wuhan, Hubei Province, central China, in December 2019 [2]. Since then, with a well-marked feature of fast dissemination by inter-human contact, in addition to its high level of virulence, the disease has brought people to an unprecedented health crisis and has forced the World Health Organization (WHO) to declare that COVID-19 has become pandemic [3]. 
Currently, the entire world registers over 21 million infected people and a number of lethal cases of approximately 760.000 [4]. However, despite being classified as a major public health problem, coronavirus disease is usually characterized by the presence of mild respiratory symptoms (cough, fever, dyspnea and fatigue) accompanied by lymphopenia. Nevertheless, in the most severe cases, it might evolve to pneumonia with an acute respiratory syndrome and sometimes lead to death [5].

In this pandemic setting, for the purpose of identifying susceptible groups, it has been shown that patients with severe SARS-CoV-2 infection share some comorbidities, such as diabetes mellitus, arterial hypertension, coronary heart disease, and previous lung disease [6]. Since all these conditions are characterized by inflammation, it is reasonable to presume that COVID-19 infection might arise in patients with chronic inflammatory rheumatic diseases [7], especially because the increased risk posed by viral infections in inflammatory disease patients is well known [8]. Furthermore, most synthetic and biologic disease-modifying antirheumatic drugs (DMARDs), currently used in rheumatologic clinical practice, have already been shown to increase both the incidence and severity of infections in general [9, 10]; thus, COVID-19 could additionally run a more severe course in these patients. However, with the increase in coronavirus scientific data, from the initial case reports to tens of reasonably well-designed studies on risk factors for COVID-19, it became clear that inflammatory rheumatic diseases were seldom included as a risk factor both for incident or severe SARS-CoV-2 infection [11]. In addition, there is evidence of some biologic DMARDs being used for the treatment of severe cases of COVID-19 [12, 13, 14], as well as hydroxychloroquine, a drug used for a long time in rheumatic diseases, which has shown some efficacy in COVID-19 treatment [15].

The diagnosis of COVID-19 acute infection is based on clinical features but preferably confirmed by the detection of viral RNA in naso/oropharyngeal swabs by nucleic acid amplification methods such as realtime reverse transcription-polymerase chain reaction (rRT-PCR) and loop-mediated isothermal amplification (LAMP) $[16,17,18]$. Serologic tests for IgG, IgA and IgM anti-SARS-CoV-2, targeting different viral antigens, have recently been implemented in clinical practice. Its value resides in confirming exposure to SARSCoV-2, including patients with negative RT-PCR results, being more effective, particularly after 10 days of symptom onset, negative [19]. Serology may also prove to be important for identifying the development of persistent COVID-19 immunity, as detected by the persistence of serum antibody positivity, particularly for IgG [20]; however, whether it could prevent recurrent infection is still unknown.

The ability to produce detectable levels of anti-SARS-CoV-2 antibodies after COVID-19 exposure seems to vary among patients. Some patients will develop high titers of $\mathrm{IgM} / \lg A$ and most importantly $\lg$, while a substantial amount of them will not present any serum antibody detected by current methods, even after a PCR-confirmed COVID-19 infection [21]. The factors, clinical or demographic, that determine one person to produce detectable antibodies after exposure are unclear. Likewise, it is also unknown whether rheumatic patients and the use of conventional or biologic DMARDs have any effect on anti-SARS-CoV-2 antibody development. 
This study aimed to assess the serologic behavior of rheumatic patients on synthetic and biologic DMARD during the COVID-19 pandemics in São Paulo, Brazil.

\section{Materials And Methods}

\section{Patient selection}

One hundred patients ( $\geq 18 \mathrm{yrs}$ ) with a diagnosis of rheumatic diseases followed by five rheumatologists (members of this research team: FMS, MOP, JBL, JFC, CPF) were enrolled in this prospective study from March 2020 to August 2020 in São Paulo, Brazil.

To ensure representativeness of using multiple different synthetic and biologic DMARDs, a convenience sampling method was performed by selecting patients according to medication use into four groups: Group 1 (no antimalarial/DMARD), Group 2 (antimalarial monotherapy), Group 3 (antimalarial plus any other synthetic DMARD) and Group 4 (antimalarial plus biologic DMARD).

\section{Clinical and demographic data}

Patients underwent a baseline clinical interview by telephone, email or office appointment to confirm medical information. Demographic and disease clinical data were collected. Patients were also asked at baseline whether they had any respiratory symptoms suggestive of COVID-19 at any time since the beginning of the pandemic. They were then weekly assessed for a total period of 12 weeks using a specific questionnaire to monitor symptoms such as cough, rhinorrhea, dyspnea, anosmia, fatigue, diarrhea and fever, as well as the need for hospitalization.

\section{Laboratory data assessment}

Study participants were scheduled for two at-home blood sample collections for anti-SARS-CoV-2 IgM and IgG identification. An automated chemiluminescence immunoassay (CLIA) for the qualitative determination of IgG and IgM antibodies against the spike (S) and nucleocapsid $(N)$ proteins from SARS-CoV-2 in human serum or plasma was run in the MAGLUMI analyzer (Snibe Diagnostics, Shenzhen China) according to the manufacturer's instructions. The results are presented in aleatory units per $\mathrm{mL}(\mathrm{AU} / \mathrm{mL})$ in comparison to calibrators also provided in the kit.

The first blood collection was drawn at baseline and the second one up to twelve weeks later. Between these two procedures, all patients were monitored through weekly telephone contact actively searching for new-onset respiratory symptoms. Symptomatic patients were referred to their treating rheumatologist to judge whether these symptoms could not be otherwise explained by previous chronic respiratory conditions. If the acute respiratory syndrome was deemed to be highly suggestive of COVID-19 infection by the treating physician, then the patient was submitted to at-home naso/oropharyngeal swab collection for SARS-CoV-2 rRT-PCR testing. The combined naso/oropharyngeal swabs were immersed in $3 \mathrm{~mL}$ of sterile saline $0.9 \%$ and transported to the lab. 
RT-PCR: An aliquot of $200 \mu \mathrm{L}$ was extracted by the DSP Virus/Pathogen kit in the automated platform QIAsymphony and eluted in $60 \mu \mathrm{L}$. Five microliters of eluate was subjected to rRT-PCR with primers and probe from the viral E gene in duplex to the cellular control RNAseP, as described [22], employing TaqMan Fast Virus 1-Step Master Mix (ThermoFisher, Brazil). A Ct value of 35 was adopted as the cut-off. The limit of detection was determined as 408 copies/mL by probit analysis using the ACCUPLEX SARS-COV-2 reference material (0505-0126, Seracare, USA).

Patients whose serologic test resulted in IgG positivity at baseline were censored and thus not submitted to the second blood collection.

\section{Statistical analysis}

All demographic and clinical variables were compared between patients according to serologic status, which was assessed in four different scenarios: positivity for any immunoglobulin (Ig) at any time, positivity for IgG at any time, seroconversion for any lg throughout the follow-up and seroconversion for IgG throughout the follow-up. Seroconversion was defined as the absence of the respective antibody at baseline followed by a later positive test.

All analyses were performed using R software version 3.5.2 (R Development Core Team, 2005). Chisquare, Fisher's exact, Mann-Whitney, Student's T, and Welch's T tests were used as appropriate. A univariate analysis was performed between baseline variables for the different serologic classifications. The significance level was set at $5 \%(p=0.05)$.

The study was approved by the local ethical board (Ethics Committee from Hospital Santa Paula) and by the national ethical board (CONEP- National Commission on Ethics and Research) at the register number CAAE: 30444020.3.0000.0008. All patients signed a written informed consent form before enrollment, and the study was conducted in accordance with the Declaration of Helsinki [23].

\section{Results}

A total of 100 patients were selected and included in the final analysis (Figure 1). The demographic data are described in Table 1. The cohort was largely represented by autoimmune rheumatic diseases. Systemic lupus erythematous (SLE) was the most common diagnosis (19\%), followed by psoriatic arthritis (PsA) (16\%) and rheumatoid arthritis (RA) (15\%). The sample size for each group was as follows: Group $1(n=28)$, Group $2(n=23)$, Group $3(n=23)$ and Group $4(n=26)$. Twenty-six $(26 \%)$ patients were not on any synthetic or biologic DMARD, including antimalarial drugs. These individuals represented a miscellaneous combination of rheumatic non-autoimmune diseases. They served the purpose of a control group (Group 4).

At baseline, 7 (7\%) patients tested positive for anti-SARS-CoV-2 antibodies, either IgG, IgM or both. Of these, 6 were positive for IgG and, hence, were censored. None except for 1 could recall any respiratory symptoms since the beginning of the pandemics. The patient who did recall respiratory symptoms 
presented four weeks before study enrollment with typical COVID-19 symptoms, including fever, fatigue, cough and dyspnea. By that time, her chest CT confirmed a highly likely COVID-19 pneumonia, and although she was admitted for a few days, no oxygen supplementation was warranted. Her recovery was unremarkable. The remaining 94 (94\%) patients were submitted to weekly follow-up and finally to the second blood test.

Thirty-three (33\%) patients presented respiratory symptoms, mostly mild, during the follow-up. None of them required admission. Nine of these cases were considered highly suggestive of COVID-19 infection and were then submitted to SARS-CoV-2 rRT-PCR testing. Three (33.3\%) were positive, and six $(66.7 \%)$ were negative. Notably, all three positive rRT-PCR patients later had detectable anti-SARS-CoV-2 IgG. Additionally, two suspected patients whose rRT-PCR results were negative also had detectable anti-SARSCoV-2 IgG in the follow-up.

Twenty-one (21\%) individuals tested positive for some anti-SARS-CoV-2 Ig at some point of the study. As expected, there was a trend for a higher incidence of respiratory symptoms among those who tested positive for some Ig compared to those who did not ( $52.6 \%$ vs. $29.1 \%, p=0.062)$. No other significant difference or trend was found when Ig-positive patients were compared to Ig-negative patients (Table 2). Fourteen (14\%) patients tested positive for anti-SARS-CoV-2 IgG at some point of the study. These patients were significantly older ( $54.3 \mathrm{yrs} \pm 8.2 \mathrm{vs} .45 .2 \mathrm{yrs} \pm 14.6, \mathrm{p}=0.002)$ than their IgG-negative counterparts. There was also a borderline significant association for more frequent use of bDMARDs in IgG-positive patients ( $42.9 \%$ vs. $19.8 \%, p=0.056)$ (Figure 2 ). It is remarkable to note that half of the patients $(50.0 \%$ ) who turned IgG positive in the study remained asymptomatic (Table 3 ). In Figure 3 , the final results for any time anti-SARS-CoV-2 positivity in the entire sample is depicted.

Potential predictors for any Ig seroconversion and specifically for IgG seroconversion were also assessed. Fourteen (14\%) patients subsequently tested positive for some anti-SARS-CoV-2 Ig at follow-up after negative baseline serology. These patients presented more frequently with respiratory symptoms during the follow-up compared to those patients who remained persistently lg negative $(64.3 \%$ vs. $27.7 \%$, $\mathrm{p}=0.012$ ) (Table 2). Eight (8\%) patients developed detectable IgG in the second serology after testing negative at baseline. A trend for a higher incidence of respiratory symptoms was found in these patients compared to those who showed no IgG seroconversion $(62.5 \%$ vs. $31.4 \%, p=0.075)$. While none of these patients were on use of SDMARD, nearly one-third of patients who remained IgG negative during the follow-up were on SDMARD, reaching borderline statistical significance $(0.0 \%$ vs. $35.4 \%, p=0.050)$ (Table $3)$.

\section{Discussion}

This was a prospective study in which all patients underwent the same standardized protocol, with blood serology by a highly accurate method at two different time points. Our study assessed the pattern of antiSARS-CoV-2 antibodies during the pandemics of COVID-19 in Brazilian rheumatic patients, and we found that fourteen percent were infected by SARS-CoV-2, as confirmed by anti-SARS-CoV-2 IgG positivity. 
Herein, although infected patients presented more often with respiratory symptoms, it is remarkable to note that asymptomatic COVID-19 infections were fairly frequent in this population (50.0\%). None of the patients showed severe COVID-19, and all patients who presented with respiratory symptoms in the study fully recovered. We also found a higher use of bDMARD and a lower use of SDMARD in those patients who turned SARS-CoV-2 IgG positive, even among asymptomatic COVID-19 infections. To date, this is the first prospective study to assess anti-SARS-CoV-2 seroconversion in rheumatic disease patients.

Synthetic and biologic DMARDs are well known for increasing both the frequency and severity of infections in rheumatic disease patients who are on chronic use [10]. Although the magnitude and propensity for specific pathogens may vary among different drugs, on average, this has been true for both bacterial and viral etiologies [8,24]. In this scenario, COVID-19 started to be a challenge to rheumatologists: whether the rheumatic diseases or their own treatment could be a risk factor for SARSCoV-2 infection or either for the outcome of coronavirus disease in those infected rheumatic patients. At first, it was reasonable to expect that autoimmune rheumatic disease patients on synthetic and/or biologic DMARDs would be particularly vulnerable to more frequent and severe COVID-19 infections. Recently, different cohorts with rheumatic patients infected by SARS-CoV-2 have been published, and this idea has been contradicted $[25,26,27,28]$. However, some authors have shown that the clinical course and disease severity of COVID-19 in these patients are closely related to what overtakes the general population. Therefore, risk factors such as age and previous cardiovascular and pulmonary diseases are likely to play a major role in determining the risk for infection severity in rheumatic disease patients [29]. Accordingly, in our study, despite synthetic and biologic DMARD users, we found no severe clinical manifestations in our infected patients. However, how the immune system in synthetic and biologic DMARD users reacts to SARS-CoV-2 exposure and the degree to which its antibody production capacity is affected is vastly unknown.

To contribute to filling in the knowledge gap on the matter, our cohort was able to show some seroconversion patterns in rheumatic disease patients on synthetic and biologic DMARDs after SARSCoV-2 exposure. Fourteen (14.0\%) percent of our cohort eventually had anti-SARS-CoV-2 IgG detected by CLIA, which has been shown to be highly specific for diagnosing COVID-19 [30]. Supporting this is the fact that all PCR-confirmed COVID-19 infections in our cohort had a later IgG titer above the upper limits and were hence considered IgG positive. We did not consider isolated anti-SARS-CoV-2 IgM positivity as a surrogate of COVID-19 infection because of the cross reaction with rheumatoid factor IgM [31], present in part of our sample. Notably, the only patient who initially tested positive for IgM and negative for IgG further tested negative for both antibodies in the follow-up blood collection. He remained asymptomatic throughout the study. A second patient whose serology was negative in the first blood exam tested positive for isolated IgM in the follow-up test. She also remained asymptomatic during the study and ever since. IgM titers can be detected before IgG increases in acute COVID-19 infections; however, persistent or transient positivity for IgM not followed by IgG detection is rather common in the authors' experience, and false positivity must be considered in these cases [21]. 
We found a statistical trend for a higher prevalence of bDMARD use in our patients who tested positive for anti-SARS-CoV-2 IgG when compared to patients not on bDMARDs. This difference must be interpreted with caution since it might simply result from a more frequent use of health services by bDMARD users than their counterparts. Hence, it should not be automatically taken as an immune promoting influence or as any sort of COVID-19 infection protective role by bDMARDs. It is, however, reassuring to notice that slightly over one quarter $(26.0 \%)$ of bDMARD patients in the study adequately produced anti-SARS-CoV-2 IgG, and none evolved into severe COVID-19 infection. Although no definitive conclusion can be drawn from these data, it does seem that bDMARD users retain their humoral immunity against SARS-CoV-2. These results are in line with the recently published data from the COVID19 Global Rheumatology Alliance, where bDMARD use was associated with less severe COVID-19 infection in autoimmune rheumatic disease patients [25].

In the opposite direction, the absence of non-antimalarial sDMARD users in those patients who seroconverted for anti-SARS-CoV-2 IgG during the follow-up must be interpreted with caution, as confounding factors might have influenced this result. For instance, different levels of SARS-CoV-2 exposure may exist between sDMARD users and non-sDMARD users. Furthermore, the lack of anti-SARSCoV-2 production may not necessarily be associated with a lack of immune response to COVID-19, as cellular immunity has been studied and seems to play a protective role in COVID-19 infection [32, 33, 34].

The strength of this cohort is based on the fact of being a prospective study analyzing the region with one of the highest COVID-19 infection incidences during the peak rate and the overwhelming health system; data reliability, as the responsible treating physicians were also members of the research team; the sensitivity and specificity of the serologic tests; and the fact that we were able to assess patients suspected for COVID-19 infection with PCR throughout the protocol.

The limitations of the study include the sample, which was comprised of patients diagnosed with a wide range of different rheumatic diseases, some of whom were not autoimmune diseases. Thus, a role for each of these conditions on SARS-CoV-2 seroconversion could not be assessed separately. Similarly, both SDMARD and bDMARD use encompassed many different drugs, and the distinct role of SARS-CoV-2 seroconversion for each of these drugs is expected and could not be assessed due to the small sample size.

Serology for COVID-19 yielded a $14 \%$ incidence in this population; half of these patients evolved asymptomatically, and none presented severe clinical manifestations. Hence, temporally withholding rheumatic patient treatment during the pandemic based on this concern is not warranted. Furthermore, bDMARD use seems not to hamper the humoral immune response to SARS-CoV-2, although no definite conclusion about this matter can be drawn from our study, and sDMARD use was associated with a lower incidence of anti-SARS-CoV-2 IgG positivity. Whether SDMARD hampers the humoral immune response, switches humoral to cellular immunity or even impacts COVID-19 infection remains to be elucidated.

\section{Declarations}


Funding: This work was supported by DASA-Brazil.

Conflicts of interest: None to disclose

Availability of data and material: The data are available upon reasonable request.

Ethics approval: The study was approved by the local ethical board (Ethics Committee from Hospital Santa Paula) and by the national ethical board (CONEP- National Commission on Ethics and Research) at the register number CAAE: 30444020.3.0000.0008.

Consent to participate: All patients signed a written informed consent form before enrollment.

Consent for publication: All authors listed here agreed to be accountable for all aspects of the work and allow the publication of this version.

Contribution Statement: All authors contributed to the study conception and design. Conceptualization: Felipe M Santana, Jayme F Cobra and Camille P Figueiredo; Methodology: Felipe M Santana, Jaqueline B Lopes, Mariana O Perez, Jayme F Cobra and Camille P Figueiredo; Formal analysis and investigation: Felipe M Santana, Jose Eduardo Levi, jayme F Cobra and Camille P Figueiredo; Original draft preparation: Felipe M Santana, Jaqueline B Lopes, Mariana O Perez and Camille P Figueiredo; Writing - review and editing: Gustavo Campana, Jose Eduardo Levi, Flavia PPL Lopes, Otavio Gebara, Jayme F Cobra and Camille P Figueiredo; Funding acquisition: Gustavo Campana, Flavia PPL Lopes, Otavio Gebara and Jayme F Cobra; Resources: Felipe M Santana, Jaqueline B Lopes, Mariana O Perez and Jayme F Cobra.

\section{References}

1. Holshue ML, DeBolt C, Lindquist S, et al. First Case of 2019 Novel Coronavirus in the United States (2020) N Engl J Med;382:929-36.

2. Burki TK (2020) Coronavirus in China. Lancet Respir Med Mar;8(3):238. doi: 10.1016/S22132600(20)30056-4.

3. Liu J, Zheng X, Tong Q, et al (2020) Overlapping and discrete aspects of the pathology and pathogenesis of the emerging human pathogenic coronaviruses SARS-CoV, MERS-CoV and 2019nCoV. J Med Virol;92:491-4.

4. World Health Organization. Coronavirus disease 2019 (COVID-19) situation report. https://www.who.int/docs/default-source/coronaviruse/situation-reports/20200817-weekly-epiupdate-1.pdf?sfvrsn=b6d49a76_4. [Accessed August, 2020].

5. Huang, C. et al (2020) Clinical features of patients infected with 2019 novel coronavirus in Wuhan, China. Lancet 395, 497-506.

6. Tian W, Jiang W, Yao J, Nicholson CJ, Li RH, Sigurslid HH, et al (2020) Predictors of mortality in hospitalized COVID-19 patients: a systematic review and meta-analysis. J Med Virol 2020 May 
22;10.1002/jmv.26050. doi: 10.1002/jmv.26050; Huang, C. et al. Clinical features of patients infected with 2019 novel coronavirus in Wuhan, China. Lancet 395, 497-

7. Figueroa-Parra G, Aguirre-Garcia GM, Gamboa-Alonso CM, Camacho-Ortiz A, Galarza-Delgado DA (2020) Are my patients with rheumatic diseases at higher risk of COVID-19? Ann Rheum Dis;79(6):839-40.

8. Tinsley A, Navabi S, Williams ED, Liu G, Kong L, Coates MD (2019) Increased risk of Influenza and Influenza-related complications among 140,480 patients with Inflammatory Bowel Disease. Inflamm Bowel Dis. Sep 18;25(10):e135.

9. Chiu YM, Chen DY (2020) Infectionrisk in patients undergoing treatment for inflammatory arthritis: non-biologics versus Expert Rev Clin Immunol. Feb;16(2):207-228. doi:

10.1080/1744666X.2019.1705785.

10. Caporali R, Caprioli M, Bobbio-Pallavicini F, Montecucco C (2008) DMARDS and infections in rheumatoid arthritis. Autoimmun Rev; 8: 139-43.

11. Grange L, Guilpain P, Truchetet ME, Cracowski JL; Société française de pharmacologie et de thérapeutique (SFPT) (2020) Challenges of autoimmune rheumatic disease treatment during COVID19 pandemic: A review. Jun 27:S0040-5957(20)30118-9. doi: 10.1016/j.therap.2020.06.013

12. Xu X, Han M, Li T, Sun W, Wang D, Fu B, et al (2020) Effective treatment of severe COVID-19 patients with tocilizumab. Proc Natl Acad Sci USA.;117(20):10970-5.

13. Luo P, Liu Y, Qiu L, Liu X, Liu D, Li J (2020) Tocilizumab treatment in COVID-19: a single center experience. J Med Virol. https://doi.org/10.1002/jmv.25801.

14. Toniati P, Piva S, Cattalini M, Garrafa E, Regola F, Castelli F, et al (2020) Tocilizumab for the treatment of severe COVID-19 pneumonia with hyperinflammatory syndrome and acute respiratory failure: a single center study of 100 patients in Brescia, Italy. Autoimmun Rev.;19(7):102568.https://doi.org/10.1016/j.autrev.2020.102568.

15. Chen, Z. et al (2020) Efficacy of hydroxychloroquine in patients with COVID-19: results of a randomized clinical trial. Preprint at medRxiv. https://doi.org/10.1101/2020.03.22.20040758.

16. Zou L, Ruan F, Huang M, Liang L, Huang H, Hong Z, et al (2020) SARS-CoV-2 Viral Load in Upper Respiratory Specimens of Infected Patients. N Engl J Med. Mar 19; 382(12):1177-1179.

17. Wang W, Xu y, Gao R, Lu R, Han K, Wu G, Tan W (2020) Detection of SARS-CoV-2 in Different Types of Clinical Specimens. Mar 11;323(18): 1843-1844.

18. Romano CM, Chebabo A, Levi JE (2020) Past, present, and future of COVID-19: a review. Braz J Med Biol Res.;53(9):e10475. doi: 10.1590/1414-431×202010475.

19. Lauer SA, Grantz KH, Bi Q, Jones FK, Zheng Q, Meredith HR, et al (2020) The Incubation Period of Coronavirus Disease 2019 (COVID-19) From Publicly Reported Confirmed Cases: Estimation and Application. Ann Intern Med. May 5;172(9):577-582.

20. Younes N, Al-Sadeq DW, AL-Jighefee H, Younes S, Al-Jamal O, Daas HI, et al (2020) Challenges in Laboratory Diagnosis of the Novel Coronavirus SARS-CoV-2. Viruses. Jun;12(6):582. 
21. Long QX, Huang Al, Deng HJ, Wu GC, Deng K, Chen YK, et al (2020) Antibody responses to SARSCoV-2 in patients with COVID-19. Nat Med. Jun;26(6):845-848.

22. Corman VM, Landt O, Kaiser M, Molenkamp R, Meijer A, Chu DK, et al (2020) Detection of 2019 novel coronavirus (2019-nCoV) by real-time RT-PCR. Euro Surveill 25: 2000045, doi:2807/15607917.ES.2020.25.3.2000045.

23. WMA Declaration of Helsinki - Ethical Principles for Medical Research Involving Human Subjects. Available from: https://www.wma.net/policy/current-policies. [Accessed March, 2020].

24. Davies R, Southwood TR, Kearsley-Fleet L, Lunt M, Hyrich KL, and on behalf of the British Society for Paediatric and Adolescent Rheumatology Etanercept Cohort Study (2020) Medically Significant Infections Are Increased in Patients with Juvenile Idiopathic Arthritis Treated with Etanercept: Results from the British Society for Paediatric and Adolescent Rheumatology Etanercept Cohort Study. Arthritis Rheumatol Sep; 67(9): 2487-2494.

25. Gianfrancesco M, Hyrich KL, Al-Adely S, Carmona L, Danila MI, et al (2020) Characteristics associated with hospitalisation for COVID-19 in people with rheumatic disease: data from the COVID19 Global Rheumatology Alliance physician-reported registry. Ann Rheum Dis. May 29. doi: 1136/annrheumdis-2020-217871.

26. Nuñes DDF, Leon L, Mucientes A, Rodriguez-Rodriguez L, Urgelles JF, Garcia AM, et al (2020) Risk factors for hospital admissions related to COVID-19 in patients with autoimune inflammatory rheumatic diseases. Ann Rheum Dis;0:1-7. doi:10.1136/annrheumdis-2020-217984.

27. Pablos JL, Galindo M, Carmona L, Lledó A, Retuerto M, Blanco R, et al (2020) Clinical outcomes of hospitalised patients with COVID-19 and chronic inflammatory and autoimune rheumatic diseases: a multicentric matched cohort studt. Ann Rheum Dis;0:1-6. doi:10.1136/annrheumdis-2020-218296.

28. Zhong J, Shen G, Yang H, Huang A, Chen X, Dong L, et al (2020) COVID-19 in patients with rheumatic disease in Hubei province, China: a multicentre retrospective observational study. Lancet Rheumatol. Jul 3 doi: 10.1016/S2665-9913(20)30227-7.

29. Fredi M, Cavazzana I, Moschetti L, Andreoli L, Franceschini F and on behalf of Brescia Rheumatology COVID-19 Study Group (2020) COVID-19 in patients with rheumatic diseases in northern Italy: a single-centre observational and case-control study. Lancet Rheumatol. Jun 18. doi: 1016/S26659913(20)30169-7.

30. Bastos ML, Tavaziva G, Abidi SK, Campbell JR, Haraoui LP, Johnston JC, et al (2020) Diagnostic accuracy of serological tests for COVID-19: systematic review and meta-analysis. BMJ; 370: m2516. doi: 1136/bmj.m2516.

31. Wang Q, Du Q, Guo B, Mu D, Lu X, Ma Q, et al. A method to present SARS-CoV-2 IgM false positive in gold immunochromatography and Enzyme-Linked Immunosorbent Assays. J Clin Microbiol. 2020 Jun; 58(6): e00375-20. doi: 1128/JCM.00375-20.

32. Tay MZ, Poh CM, R'enia L, MacAry PA, Ng LFP (2020) The trinity of COVID-19: immunity, inflammation and intervention. Nat Rev Immunol. Apr 28:1-12. 
33. Manners C, Bautista EL, Sidoti H and Lopez OJ (2020) Protective adaptative immunity against Severe Acute Respiratory Syndrome Coronaviruses 2 (SARS-CoV-2) and implications for vaccines. Cureus. jun;12(6):e8399.

34. Vabret N, Britton GJ, Gruber C, Hedge S, Kim J, Kuksin M, et al (2020) and The Sinai Immunology Review Project. Immunology of COVID-19: current state of the science. Immunity. Jun 16;52(6):91041.

\section{Tables}

TABLE 1. Demographic and clinical characteristics of RD patients enrolled in the study 


\begin{tabular}{|c|c|}
\hline & $N=100$ \\
\hline Age (years), mean (SD) & $46.5(14.2)$ \\
\hline \multicolumn{2}{|l|}{ Sex, $n(\%)$} \\
\hline Men & $15(15.0 \%)$ \\
\hline Women & $85(85.0 \%)$ \\
\hline Months since RD diagnosis, median (IQR) & $36(21-80)$ \\
\hline \multicolumn{2}{|l|}{ RD activity, $\mathrm{n}(\%)$} \\
\hline Remission & $49(73.1 \%)$ \\
\hline Mild & $8(11.9 \%)$ \\
\hline Moderate & $6(9.0 \%)$ \\
\hline Severe & $4(6.0 \%)$ \\
\hline Respiratory symptoms, n (\%) & $33(33.0 \%)$ \\
\hline \multicolumn{2}{|l|}{ Groups according to therapy, $\mathrm{n}(\%)$} \\
\hline Group 1 & $28(28.0 \%)$ \\
\hline Group 2 & $23(23.0 \%)$ \\
\hline Group 3 & $23(23.0 \%)$ \\
\hline Group 4 & $26(26.0 \%)$ \\
\hline Antimalarial use, n (\%) & $74(74.0 \%)$ \\
\hline sDMARD use, $\mathrm{n}(\%)$ & $31(31.0 \%)$ \\
\hline Months on sDMARD use, median (IQR) & $7(3-31)$ \\
\hline bDMARD use, $\mathrm{n}(\%)$ & $23(23.0 \%)$ \\
\hline Months on bDMARD use, median (IQR) & $16(1-45)$ \\
\hline GC use, $n(\%)$ & $43(43.0 \%)$ \\
\hline GC dose ${ }^{1}$, median (IQR) & $0(0-3)$ \\
\hline
\end{tabular}

$S D$, standard deviation; RD, rheumatic disease; IQR, interquartile range; SDMARD, synthetic DMARD; bDMARD, biologic DMARD; GC, glucocorticoid.

${ }^{1}$ prednisone or equivalent to prednisone. 
TABLE 2. Baseline characteristics of patients according to immunoglobulin (Ig) positivity at any time point and seroconversion to Ig during the study. 


\begin{tabular}{|c|c|c|c|c|c|c|}
\hline & $\begin{array}{l}\text { Ig Neg } \\
(n=79)\end{array}$ & $\begin{array}{l}\text { Ig Pos } \\
(n=21)\end{array}$ & $\mathbf{p}$ & $\begin{array}{l}\text { Seroconv.lg } \\
\text { Neg } \\
(n=85)\end{array}$ & $\begin{array}{l}\text { Seroconv.lg } \\
\text { Pos } \\
(n=14)\end{array}$ & $\mathbf{p}$ \\
\hline Age (years), mean (SD) & $\begin{array}{l}45.6 \\
(14.4)\end{array}$ & $\begin{array}{l}49.8 \\
(13.0)\end{array}$ & 0.238 & $46.4(14.3)$ & $46.7(14.3)$ & 0.936 \\
\hline Sex, $n(\%)$ & & & 1.000 & & & 1.000 \\
\hline Men & $\begin{array}{l}12 \\
(15.2 \%)\end{array}$ & $\begin{array}{l}3 \\
(14.3 \%)\end{array}$ & & $13(15.3 \%)$ & $2(14.3 \%)$ & \\
\hline Women & $\begin{array}{l}67 \\
(84.8 \%)\end{array}$ & $\begin{array}{l}18 \\
(85.7 \%)\end{array}$ & & $72(84.7 \%)$ & $12(85.7 \%)$ & \\
\hline $\begin{array}{l}\text { Months since RD diagnosis, } \\
\text { median (IQR) }\end{array}$ & $\begin{array}{l}36(64- \\
20)\end{array}$ & $\begin{array}{l}60(24- \\
96)\end{array}$ & 0.399 & $36(19-69)$ & $60(28-105)$ & 0.219 \\
\hline RD activity, $\mathrm{n}(\%)$ & & & 0.680 & & & \\
\hline Remission & $\begin{array}{l}36 \\
(70.6 \%)\end{array}$ & $\begin{array}{l}13 \\
(81.2 \%)\end{array}$ & & $40(71.4 \%)$ & $8(80.0 \%)$ & \\
\hline Mild & $\begin{array}{l}7 \\
(13.7 \%)\end{array}$ & $\begin{array}{l}1 \\
(6.2 \%)\end{array}$ & & $7(12.5 \%)$ & $1(10.0 \%)$ & \\
\hline Moderate & $\begin{array}{l}4 \\
(7.8 \%)\end{array}$ & $\begin{array}{l}2 \\
(12.5 \%)\end{array}$ & & $5(8.9 \%)$ & $1(10.0 \%)$ & \\
\hline Severe & $\begin{array}{l}4 \\
(7.8 \%)\end{array}$ & $\begin{array}{l}0 \\
(0.0 \%)\end{array}$ & & $4(7.1 \%)$ & $0(0.0 \%)$ & \\
\hline Respiratory symptoms, n (\%) & $\begin{array}{l}23 \\
(29.1 \%)\end{array}$ & $\begin{array}{l}10 \\
(52.6 \%)\end{array}$ & 0.062 & $23(27.7 \%)$ & $9(64.3 \%)$ & 0.012 \\
\hline $\begin{array}{l}\text { Groups according to therapy, } \\
\mathrm{n}(\%)\end{array}$ & & & 0.655 & & & 0.888 \\
\hline Group 1 & $\begin{array}{l}24 \\
(30.4 \%)\end{array}$ & $\begin{array}{l}4 \\
(19.0 \%)\end{array}$ & & $24(28.2 \%)$ & $4(28.6 \%)$ & \\
\hline Group 2 & $\begin{array}{l}17 \\
(21.5 \%)\end{array}$ & $\begin{array}{l}6 \\
(28.6 \%)\end{array}$ & & 20 (23.5\%) & $2(14.3 \%)$ & \\
\hline Group 3 & $\begin{array}{l}17 \\
(21.5 \%)\end{array}$ & $\begin{array}{l}6 \\
(28.6 \%)\end{array}$ & & $19(22.4 \%)$ & $4(28.6 \%)$ & \\
\hline Group 4 & $\begin{array}{l}21 \\
(26.6 \%)\end{array}$ & $\begin{array}{l}5 \\
(23.8 \%)\end{array}$ & & $22(25.9 \%)$ & $4(28.6 \%)$ & \\
\hline Antimalarial use, n (\%) & $\begin{array}{l}58 \\
(73.4 \%)\end{array}$ & $\begin{array}{l}16 \\
(76.2 \%)\end{array}$ & 1.000 & $63(74.1 \%)$ & $10(71.4 \%)$ & 1.000 \\
\hline sDMARD use, $\mathrm{n}(\%)$ & $\begin{array}{l}24 \\
(32.0 \%)\end{array}$ & $\begin{array}{l}8 \\
(38.1 \%)\end{array}$ & 0.609 & $28(34.6 \%)$ & $4(28.6 \%)$ & 0.767 \\
\hline Months on sDMARD use, & $7(3-25)$ & $7(5-60)$ & 0.490 & $1(0-9)$ & $5(1-7.5)$ & 0.499 \\
\hline
\end{tabular}




\begin{tabular}{|c|c|c|c|c|c|c|}
\hline bDMARD use, n (\%) & $\begin{array}{l}17 \\
(21.5 \%)\end{array}$ & $\begin{array}{l}6 \\
(28.6 \%)\end{array}$ & 0.562 & $20(23.5 \%)$ & $2(14.3 \%)$ & 0.729 \\
\hline $\begin{array}{l}\text { Months on bDMARD use, } \\
\text { median (IQR) }\end{array}$ & $\begin{array}{l}24(2- \\
48)\end{array}$ & $\begin{array}{l}12(0- \\
36)\end{array}$ & 0.515 & $15(2-48)$ & $9(0-25)$ & 0.433 \\
\hline GC use, n (\%) & $\begin{array}{l}36 \\
(42.4 \%)\end{array}$ & $\begin{array}{l}7 \\
(50.0 \%)\end{array}$ & 0.772 & $34(40.5 \%)$ & $8(57.1 \%)$ & 0.260 \\
\hline GC dose $^{1}$, median (IQR) & $0(0-3)$ & $3(0-3)$ & 0.171 & $0(0-3)$ & $3(0-4)$ & 0.373 \\
\hline
\end{tabular}

$S D$, standard deviation; RD, rheumatic disease; IQR, interquartile range; SDMARD, synthetic DMARD; bDMARD, biologic DMARD; GC, glucocorticoid.

1 prednisone or equivalent to prednisone.

Results that reached statistical significance $(p<0.05)$ or a trend toward it $(p=0.05-0.1)$ are highlighted in bold.

TABLE 3. Baseline characteristics of patients according to immunoglobulin $\mathbf{G}$ (IgG) positivity at any time point and seroconversion to IgG during the study. 


\begin{tabular}{|c|c|c|c|c|c|c|}
\hline & $\begin{array}{l}\text { IgG } \\
\text { Neg } \\
(n=86)\end{array}$ & $\begin{array}{l}\text { IgG Pos } \\
(n=14)\end{array}$ & $\mathbf{p}$ & $\begin{array}{l}\text { Seroconv.lgG } \\
\text { Neg } \\
(n=86)\end{array}$ & $\begin{array}{l}\text { Seroconv.lgG } \\
\text { Pos } \\
(n=8)\end{array}$ & $p$ \\
\hline Age (years), mean (SD) & $\begin{array}{l}45.2 \\
(14,6)\end{array}$ & $\begin{array}{l}54.3 \\
(8,2)\end{array}$ & 0.002 & $45.2(14.6)$ & $51.4(9.3)$ & 0.246 \\
\hline Sex, $n(\%)$ & & & 0.687 & & & 1.000 \\
\hline Men & $\begin{array}{l}14 \\
(16.3 \%)\end{array}$ & $1(7.1 \%)$ & & $14(16.3 \%)$ & $1(12.5 \%)$ & \\
\hline Women & $\begin{array}{l}72 \\
(83.7 \%)\end{array}$ & $\begin{array}{l}13 \\
(92.9 \%)\end{array}$ & & $72(83.7 \%)$ & $7(87.5 \%)$ & \\
\hline $\begin{array}{l}\text { Months since RD } \\
\text { diagnosis, median (IQR) }\end{array}$ & $\begin{array}{l}36(19- \\
67)\end{array}$ & $\begin{array}{l}54(25- \\
105)\end{array}$ & 0.384 & $36(19-67)$ & $54(28-111)$ & 0.361 \\
\hline RD activity, $\mathrm{n}(\%)$ & & & 0.401 & & & 1.000 \\
\hline Remission & $\begin{array}{l}39 \\
(684 \%)\end{array}$ & $\begin{array}{l}10 \\
(100.0 \%)\end{array}$ & & $39(68.4 \%)$ & $5(100.0 \%)$ & \\
\hline Mild & $\begin{array}{l}8 \\
(14.0 \%)\end{array}$ & $0(0.0 \%)$ & & $8(14.0 \%)$ & $0(0.0 \%)$ & \\
\hline Moderate & $\begin{array}{l}6 \\
(10.5 \%)\end{array}$ & $0(0.0 \%)$ & & $6(10.5 \%)$ & $0(0.0 \%)$ & \\
\hline Severe & $\begin{array}{l}4 \\
(7.0 \%)\end{array}$ & $0(0.0 \%)$ & & $4(7.0 \%)$ & $0(0.0 \%)$ & \\
\hline $\begin{array}{l}\text { Respiratory symptoms, } n \\
\text { (\%) }\end{array}$ & $\begin{array}{l}27 \\
(31.4 \%)\end{array}$ & $\begin{array}{l}6 \\
(50.0 \%)\end{array}$ & 0.211 & $27(31.4 \%)$ & $5(62.5 \%)$ & 0.075 \\
\hline $\begin{array}{l}\text { Groups according to } \\
\text { therapy, } \mathrm{n}(\%)\end{array}$ & & & 0.111 & & & 0.253 \\
\hline Group 1 & $\begin{array}{l}26 \\
(30.2 \%)\end{array}$ & $\begin{array}{l}2 \\
(14.3 \%)\end{array}$ & & $26(30.2 \%)$ & $2(25.0 \%)$ & \\
\hline Group 2 & $\begin{array}{l}17 \\
(19.8 \%)\end{array}$ & $\begin{array}{l}6 \\
(42.9 \%)\end{array}$ & & $17(19.8 \%)$ & $2(25.0 \%)$ & \\
\hline Group 3 & $\begin{array}{l}22 \\
(25.6 \%)\end{array}$ & $1(7.1 \%)$ & & $22(25.6 \%)$ & $0(0.0 \%)$ & \\
\hline Group 4 & $\begin{array}{l}21 \\
(24.4 \%)\end{array}$ & $\begin{array}{l}5 \\
(35.7 \%)\end{array}$ & & $21(24.4 \%)$ & $4(50.0 \%)$ & \\
\hline Antimalarial use, $\mathrm{n}(\%)$ & $\begin{array}{l}65 \\
(75.6 \%)\end{array}$ & $\begin{array}{l}9 \\
(64.7 \%)\end{array}$ & 0.511 & $65(75.6 \%)$ & $4(50.0 \%)$ & 0.202 \\
\hline sDMARD use, $n(\%)$ & $\begin{array}{l}29 \\
(35.4 \%)\end{array}$ & $\begin{array}{l}3 \\
(21.4 \%)\end{array}$ & 0.373 & $29(35.4 \%)$ & $0(0.0 \%)$ & 0.050 \\
\hline Months on sDMARD use, & $6(4-$ & $60(30-$ & 0.456 & $1(0-7.5)$ & $0(0-0)$ & 0.180 \\
\hline
\end{tabular}




\begin{tabular}{|c|c|c|c|c|c|c|}
\hline median (IQR) & 24) & 66) & & & & \\
\hline bDMARD use, n (\%) & $\begin{array}{l}17 \\
(19.8 \%)\end{array}$ & $\begin{array}{l}6 \\
(42.9 \%)\end{array}$ & 0.056 & $17(19.8 \%)$ & $2(25.0 \%)$ & 0.661 \\
\hline $\begin{array}{l}\text { Months on bDMARD use, } \\
\text { median (IQR) }\end{array}$ & $\begin{array}{l}24(2- \\
48)\end{array}$ & $\begin{array}{l}12(0- \\
36)\end{array}$ & 0.515 & $24(2-48)$ & $9(0-25)$ & 0.391 \\
\hline GC use, n (\%) & $\begin{array}{l}36 \\
(42.4 \%)\end{array}$ & $\begin{array}{l}7 \\
(50.0 \%)\end{array}$ & 0.772 & $36(42.4 \%)$ & $3(37.5 \%)$ & 1.000 \\
\hline GC dose ${ }^{1}$, median (IQR) & $0(0-4)$ & $1(0-3)$ & 0.846 & $0(0-4)$ & $0(0-3)$ & 0.610 \\
\hline
\end{tabular}

$S D$, standard deviation; RD, rheumatic disease; IQR, interquartile range; SDMARD, synthetic DMARD; bDMARD, biologic DMARD; GC, glucocorticoid.

1 prednisone or equivalent to prednisone.

Results that reached statistical significance $(p<0.05)$ or a trend toward it $(p=0.05-0.1)$ are highlighted in bold.

\section{Figures}




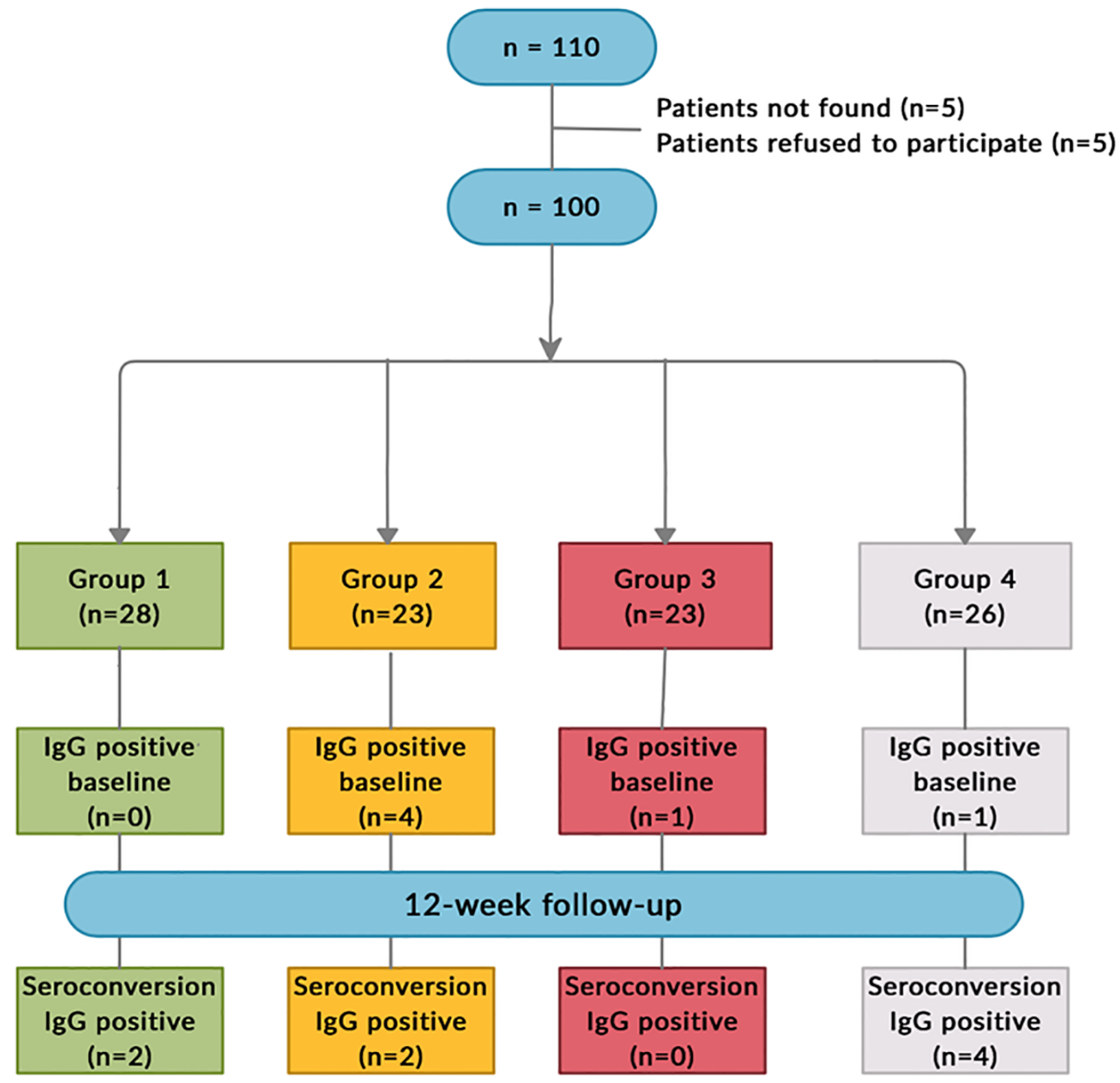

Figure 1

Schematic overview of the study design. Prospective study with four treatment arms. A total of 100 patients with rheumatic diseases were enrolled. Six of these patients had detectable anti-SARS-CoV-2 IgG at baseline. All patients were followed for up to 12 weeks with regular weekly telephone contact actively searching for incident respiratory symptoms. Seroconversion for anti-SARS-CoV-2 IgG was found in eight patients. 


\section{Percentage of bDMARD use}

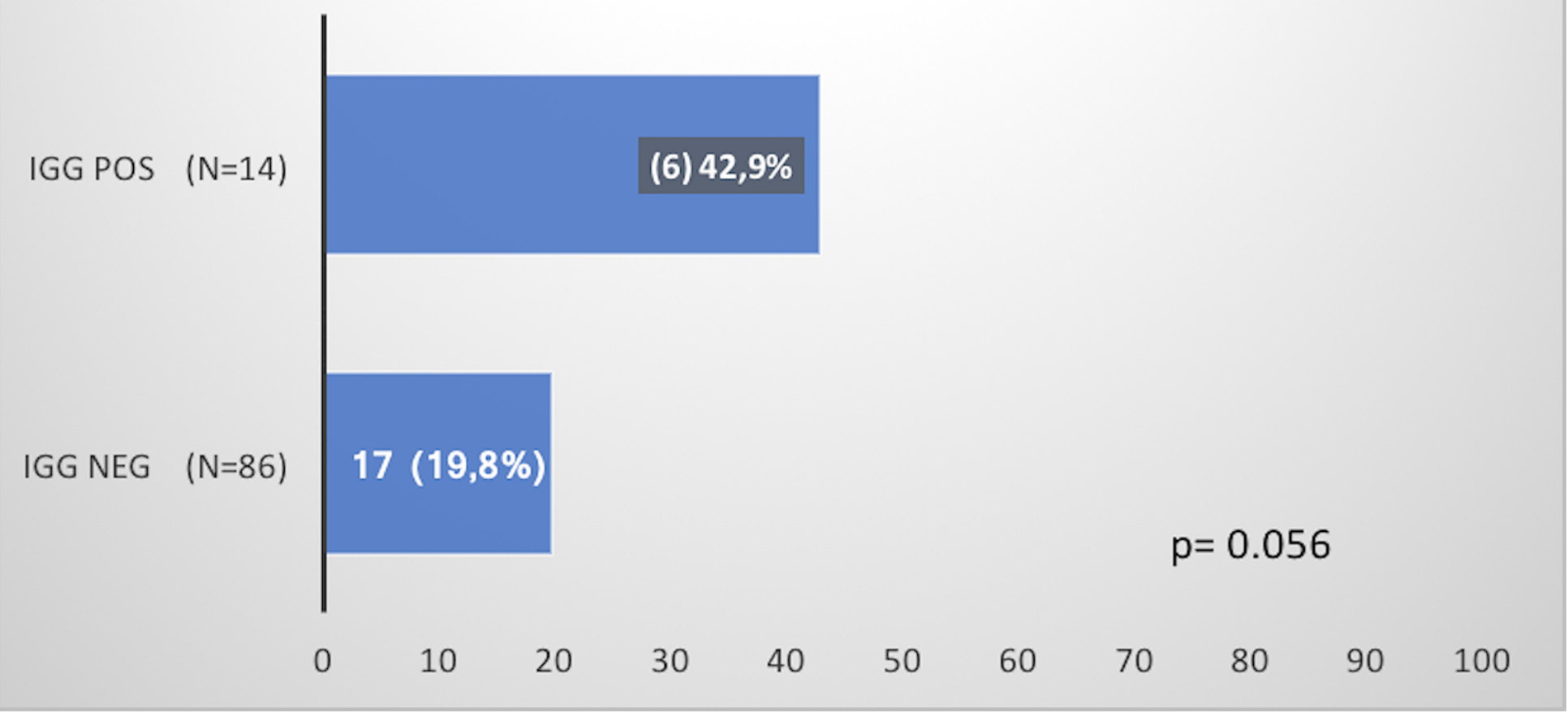

Figure 2

Distribution of biologic disease-modifying anti-rheumatic drug (bDMARD) users in anti-SARS-CoV-2 IgG seroconverted patients.

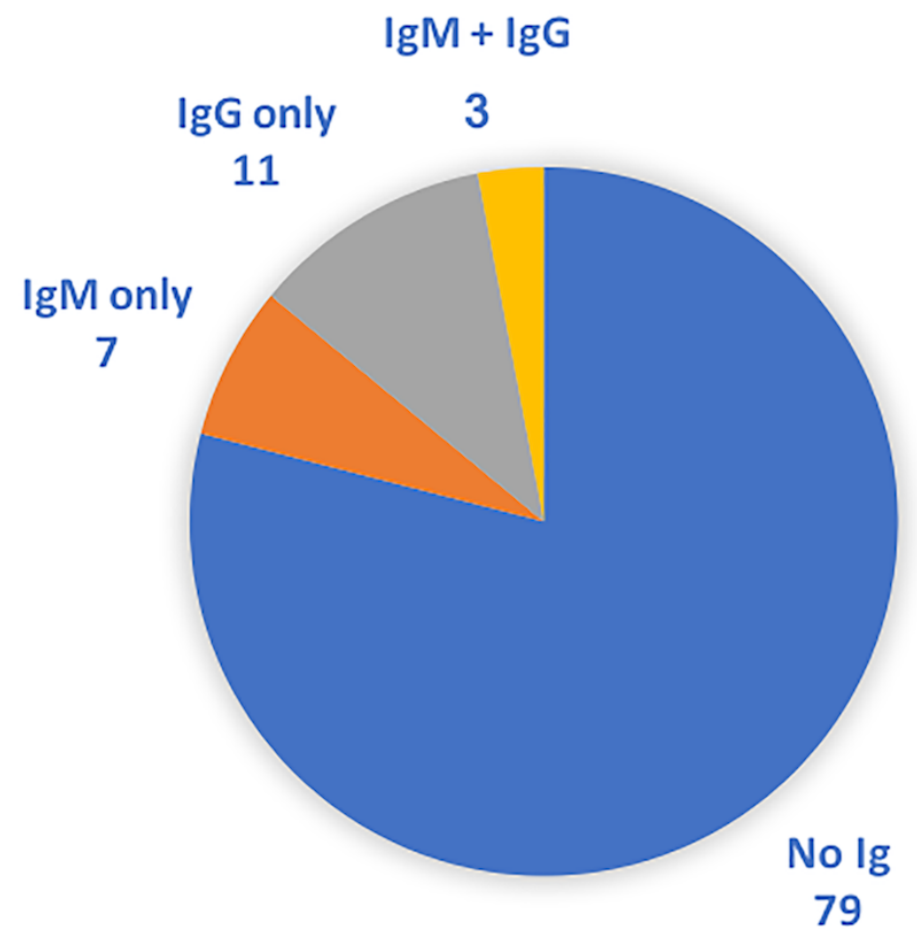


Figure 3

Prevalence of any time anti-SARS-CoV-2 antibody positivity in study patients. Only $20 \%$ of them evolved to anti-SARS-CoV-2 positivity for either IgG, IgM or both. 